\title{
Medicines from Plants with Special Reference to Herbal Products in Great Britain
}

\author{
E. J. Shellard ${ }^{1,2,3}$
}

Received: August 20, 1986

\begin{abstract}
Plants have been used as medicinal agents from the earliest days of man's existence. But over the years the rational use of plant materials became intermingled with their irrational use and this was the situation in Great Britain at the end of the 17 th century when there was the beginning of a major change in the social life of the country and people began to leave the villages. The establishment of large industrial connurbations led to the introduction of herbal products based on both useful and useless plants. They were the main source of medication for the working class until the introduction of the National Health Service in 1948 after which their sales declined.

However, during the past 20 years there has been a resurgence of interest in medicines prepared from plants but modern scientific knowledge about plants and their constituents makes it essential that more effective herbal products should be made available for sale to the general public. The Department of Health intends to ensure this but there are many problems, which are probably common to other countries, that have to be overcome in order to achieve this objective.
\end{abstract}

In order to understand and appreciate the present situation regarding herbal products it is necessary to review, very briefly, the history of the use of plants for medicinal purposes. While it may be true that originally the plants were selected on a rational basis, there is no doubt that as the more primitive societies developed they became influenced by religion, magic, and mysticism and these philosophies and ideologies must have influenced the choice of plants so that they were more frequently selected on an irrational basis. Many different theories of disease were thought out and the choice of plants depended on these ideas - the hot-cold, wet-dry theory is particularly evident during many centuries of medical treatment. Then there was the Paracelsian Doctrine of Signatures, though this was not exclusive to Europe, in the 16th century. Although it is possible that Paracelsus was justified in claiming that the plants he used had some apparent relationship with the diseases for which he used them, that was not a justification for medical practitioners in the Middle Ages collecting plants and then trying to find a disease for which they could be used based solely on their appearence or habitat. The fact is that as a result of all these ideas, and without discussing the many different concepts of medicine, all over the world the rational became mixed up with

\footnotetext{
${ }^{1}$ Emeritus Professor of Pharmacognosy, University of London, U.K.

${ }^{2}$ Sometime President, Medical Plants Section, F.I.P.

${ }^{3}$ Address for correspondence: 244 Ellerdine Road, Hounslow TW3 2PY, U.K.
}

the irrational and there is no better example than Rauwolfia serpentina - known in the Indian Bazaars for centuries as the Insanity Root because of its tranquilising properties and also as a cure for snake-bite simply because of the undulating nature of the roots in the ground. Many examples of this mixture of the rational and irrational may be found in the early books dealing with medicine and plants and in the many famous Herbals. Thus, throughout Europe during the Middle Ages and for many years later the practice of medicine as it involved plants was based on this lack of real knowledge about the medicinal value of the plants that were used - and the relics of this ignorance still persists today. Nevertheless there is plenty of evidence to suggest that many of the serfs and peasants living in the countryside had a good knowledge of the medicinal virtues of the plants which grew in their localities based on information passed on, over the centuries, by their parents and grandparents - a knowledge which also persists today in some remote rural areas.

However, herbal products i.e. prepacked medicinal preparations made from plants in large quantities and sold to the general public without any prior diagnosis were introduced as a consequence of the great social and political transformation from feudalism to capitalism which occurred in England towards the end of the 17th century and the beginning of the 18th century. The introduction of small manufacturing units meant that hundreds of people left the countryside in order to find employment in the newly developing industrial areas. The long hours of work and the squalid conditions in which they were obliged to live led to much illness and disease. The physicians were not interested in the medical problems of working class families because they were too poor to pay for treatment and as a consequence, people who were still living in the countryside and who had some knowledge about plants and their medicinal uses, collected plants and then set up stalls in the markets of the new small towns that were being built - chiefly in the Midlands, Lancashire, and Yorkshire. The freshly collected herbs and later dried herbs had a ready sale among the workers. But this also provided opportunities for unscrupulous traders to exploit the ignorance of the people now forming the great working class who were losing their links with the countryside but who believed, instinctively, in the medicinal value of plants. As the years went by it became impossible for members of the general public living in urban areas to distinguish a genuine herbalist from an impostor. Furthermore, the development of maritime power led to the import of many crude drugs from all parts of the world and this made identification very difficult with the re- 
sult that many of the drugs used were not genuine. It might be mentioned in passing that the Pharmaceutical Society of Great Britain, when founded in 1841, made the elimination of fraud as far as crude drugs and medicinal plants were concerned as its chief priority.

But long before this, the market vendors - and those who had set up permanent shops - ceased to sell herbs or simple herbal preparations and began to prepare medicines, pills, ointments, etc., initially on their own premises, to sell to their customers. It was inevitable that sooner or later some vendors would concentrate on making large quantities of these products and sell them wholesale to different retailers such as grocers, other herbalists, and general stores who proceeded to sell them to all and sundry as 'over the counter' herbal products. One consequence of this development was the attempt by a number of the more honest herbalists to set up as Medical Herbal Consultants and to establish a professional body which would protect their interests. This was the forerunner of the present-day National Institute of Medical Herbalists. The significance of this is that they practised Holistic Medicine so that after a detailed consultation and their diagnosis they prepared a medicine containing small doses of a large number of herbal extracts, the regimen being specific for that particular client.

There were also manufacturers of prepacked medicines based on inorganic chemicals and all these prepacked manufactured products became known as 'Patent Medicines'. They were secret formulations and their sales became tremendous. By the middle of the 19th century when many of the urban connurbations had grown into large towns and cities, many of the workers had learnt to read and write and then the power of the advertisements became so great that Patent Medicines became the main source of medical treatment for thousands of working class families throughout the country. Apart from the fact that different governments obtained a large revenue by means of a 'Patent Medicine Stamp Duty' there was no restriction on their sale or any concern about their contents. As far as the herbal preparations were concerned there were many different formulations chiefly based on medieval remedies some of which were effective but the majority of which were not. In the early part of the 20th century there was some restriction placed on advertisements making claims for certain cures such as cancer, tuberculosis, Bright's disease and venereal disease while in the 1930s there was the removal of the Stamp Duty provided the main ingredients of the product were disclosed on the label. This exposed many of the preparations as fraudulent and they disappeared from the market. Nevertheless, the sales of herbal products remained high until the 1948 National Health Service Act made medical treatment available to all without any charge.

Now, as already mentioned, within the last 20 years there has been this resurgence of interest in medicines from plants and it gave herbal product manufacturers the opportunity to introduce new products, more attractively packed and supported by a wide range of advertisements such as leaflets, advertisements in popular magazines and on radio and T. V. Many paper-back booklets and pamphlets have been written giving much information about plants and their medicinal properties. Unfortunately nearly all of them have been written by people who know little about plants and even less about their medicinal properties, most of the information being taken from books published during the last century. Likewise, many of the products are still unsatisfactory as far as efficacy is concerned since they are based either on the irrational uses or on the holistic formulations given by Medical Herbalists and so contain small doses of many herbs. Since most purchasers are interested in the symptomatic treatment of various illnesses the majority of products are not very effective.

However, the situation is not the same today as it was $100-$ 150 years ago nor even what it was 20 years ago. Legislation introduced in 1968 following the thalidomide tragedy has led to a far greater control over medicines - medicines of all kinds. The Medicines Act 1968 classified medicines into three groups Prescription Only Medicines (POM), those which can be sold only by a pharmacist, and those which can be sold by anyone. The Act made it illegal to manufacture or sell any of these medicines unless they had been granted a Product Licence and this was only done when the Committee for the Safety of Medicines was satisfied that any ingredient of a medicine was safe and efficacious. As far as a synthetic organic chemical was concerned this necessitated a long and expensive examination of the chemical. Its pharmacological properties had to be well defined and proven by means of suitable animal experiments after which it was subjected to stringent tests to determine its toxicity, acute toxicity, chronic toxicity, foetal toxicity, and effect on fertility; mutagenic and carcinogenic responses had to be determined as well as its pharmacodynamic and pharmacokinetic properties. Only when the CSM was satisfied with the results would it issue a licence for clinical trials to be undertaken in patients which were expected to note not only the efficacy of the drug but also any adverse reactions. The manufacturing processes were also subject to controls including quality controls. All in all, a lengthy and expensive procedure.

When the Medicines Act 1968 became effective it was realised that there were many products on the market which could not be examined in this way and they were given temporary licences - Product Licence of Right - and it was made clear that as soon as circumstances permitted these products would be examined to see if they complied with standards of efficacy, safety, and quality. Four years ago the Medicines Commission established a Committee for the Review of Medicines and announced that the examination of all products having Product Licences of Right would be completed by 1988 . This has since been amended to 1990 - probably in accordance with an E.E.C. directive regarding herbal products in all the E.E.C. countries. This decision has created a crisis among the manufacturers of herbal products. It came as a shock especially as the first indications were that herbal medicines would be subject to the same strict requirements as medicines based on chemicals. This has now been amended but it is still necessary for the manufacturer to supply evidence of efficacy and safety and quality.

With the developments in modern chromatographic techniques the problems of quality control can, to a large extent, be solved though there are still many problems associated with the selection of the crude drug or medicinal plant since natural products are variable and their quality depends upon so many factors. However, it is the question of efficacy and safety which presents the greatest problems. There is, of course, plenty of evidence to show how effective a particular herbal product has been as far as individual purchasers of the product are concerned but the CRM is not likely to accept anecdotal evidence as proof of efficacy. There is also the fact that inspite of the consumption over the years of tons of almost every herb used in herbal products there are no known cases of liver cancer, mal-formed babies, or other toxic effects as a result of these herbs. But the CRM is likely to argue that where such casualties did occur no one thought of asking whether the person had taken any herbal preparations and this is a relevant point in view of recent research into the constituents of certain plants or the reports of various toxic symptoms following the 
consumption of herbal products. These reports, however, may not be very reliable and the research may not be scientifically based but they need answering.

As a result of some political pressure by the herbal product manufacturers, the Department of Health has made two apparent concessions in connection with proof of efficacy and safety of products made solely from plants which have been used traditionally for the treatment of various symptoms. The CRM will consider appropriate bibliographies or similar publications relating to the use of the active ingredients in identical or similar disease states as sufficient evidence that efficacy has been established. Relevant references must accompany the applications. The second concession concerns toxicity. No experimental data is required but the applicant is required to indicate that there are no references in the literature to any toxicity as far as the plants in question are concerned. There is a major difference between these two concessions. As far as efficacy is concerned there must be some positive evidence so that if there are no references in the literature to the plant or its constituents it may be difficult to prove efficacy but for toxicity it is necessary to show that there are no references in the literature to the plant or any of its constituents. But searching the literature is a lengthy and expensive procedure and there can be no guarantee that the search has been complete. The CRM has access to numerous references to reported toxic effects many of which are trivial and not always based on sound scientific evidence and it is necessary to refute these claims.

While these concessions may be very helpful in many cases they can present problems especially where the bibliographies refer to isolated constituents. The therapeutic activity of a plant does not depend solely upon a single readily identifiable constituent but upon the total chemical nature of the plant or more specifically the chemical nature of the plant extract used in the product. The specific pharmacological activity of a constituent may easily be modified by other constituents present. There are numerous examples of this. But it also presents problems for the manufacturers regarding the choice of solvent for preparing the extracts. Valerian is one important plant to which special attention must be given. It should be stated that medicines based on isolated constituents only or even containing such a constituent in addition to a plant extract are not considered to be herbal products within the definition laid down by the Department of Health. Another unsatisfactory aspect is that no consideration appears to have been given to the dose levels in the herbal products. As stated earlier the majority of herbal products under review contain small doses of numerous herbs. Any attempt to modify this formulation by reducing the number of herbs in the product to one or two and increasing the dose level to make them really effective is likely to result in this product being regarded as a new product and thus subject to the full experimental evidence for safety and efficacy. Furthermore the concessions refer only to herbs which have already been on sale for the treatment of certain illnesses so that any plant being introduced for the first time or recommended for a different illness are excluded from the special treatment. Two such plants are Feverfew (Tanacetum parthenium) and Devil' Claw (Harpagophytum procumbens).

The major stumbling block to the issue of Product Licences for many plants is the lack of evidence from clinical trials as required by the Medicines Commission. These are double-blind trials, for which a licence is required - and which need to be undertaken by physicians in a hospital and approved by the hospital Ethics Committee. Individual physicians are reluctant to try out a herbal medicine, even on an informal basis. Physicians, in the main, are very sceptical of the value of plant medicines - indeed, many of them are very ignorant about plant medicines digoxin is often thought of as a synthetic chemical.

The British Medical Association has shown some concern about this increased interest in herbal medicine and recently established a Commision to consider its impact on orthodox medicine. The Pharmaceutical Society is reluctant to make any clear policy statement and both these learned bodies tend to regard herbal products as mere placebos - and, indeed many of those under review can only be considered in this way. What is required is a more positive approach to the way in which modern scientifically based herbal products can be used, thus taking on a complementary role to the more expensive and toxic synthetic compounds where these are not absolutely essential or, in many cases, desirable.

In addition to the problems of efficacy and safety and to the wider social and political questions, there are scientific problems related to the quality of the plant materials used and this concerns analytical standards. All pharmacognosists are aware of the variations which occur in plant materials obtained from identical botanical species. Chemical races, edaphic factors, methods of collection etc. all affect the nature or quantities of the constituents while the possibility of accidental adulteration or substitution cannot be ruled out so that strict analytical control is essential. Modern analytical techniques can be used even with those plants which do not appear to have any well defined constituent that can be used as a marker in a chromatographic examination. Quality control of the plant materials and of the finished products seem to be the least difficult of all the problems that require solutions if herbal products are to become readily acceptable medicines, even for those people who wish to purchase them based on their self-diagnosis.

These problems are not specific to Great Britain - they exist in all countries which have a tradition of herbal medicine and are now attempting to introduce herbal products on a modern scientific basis. In order to solve these problems a collective effort is required. 